\title{
Rupture of the myocardium in autopsied MI hearts
}

\author{
Valesca Bizinoto Monteiro ${ }^{1}$, Bianca Gonçalves Silva Torquato ${ }^{1}$, Guilherme Ribeiro Juliano ${ }^{1}$, Bárbara Cecílio da Fonseca ${ }^{1}$,

 \\ Mara Lúcia da Fonseca Ferraz ${ }^{1}$, Vicente de Paula Antunes Teixeira ${ }^{1}$, Edson Luiz Fernandes ${ }^{4}$



\section{SUMMARY}

Although myocardial rupture occurs in only $2 \%$ to $4 \%$ of cases of acute myocardial infarction (AMI), there is a high mortality rate due to acute cardiogenic shock. We present the anatomopathological findings of three cases of myocardial rupture in autopsied hearts in the last 30 years, with a diagnosis of cardiac rupture in acute myocardial infarction. In these 30 years the percentage of AMI with myocardial rupture was $0.2 \%$. Risk factors for post-AMI myocardial rupture include older age, atherosclerosis, diabetes mellitus and systemic arterial hypertension.

Keywords: autopsy, cardiac rupture, cardiogenic shock, myocardial infarction.

\section{INTRODUCTION}

Although the rupture of the myocardium occurs in only 2 to $4 \%$ of the cases of acute myocardial infarction (AMI), it is associated with high mortality mainly due to the state of acute cardiogenic shock. This occurs in about $90 \%$ of the ruptures of the left ventricular free wall and in $50 \%$ of the cases with rupture of the septum, with 5 to $24 \%$ of deaths being caused by AMI. ${ }^{1}$ The clinical/physical signs and symptoms include chest pain, dyspnea, bradycardia and shock. ${ }^{2}$ The main risk factors for cardiac rupture in patients not treated with thrombotic medication include older age, female gender, and the concurrence of systemic arterial hypertension, smoking habit, sedentary life style and diabetes mellitus. ${ }^{2}$

Myocardial rupture post-AMI occurs in total arterial occlusion as often as in cases with low collateral flow to the infarcted area. ${ }^{3}$ The most affected coronary arteries are the right (46\%), the left anterior descending (42\%), and the left circumflex (11.53\%). ${ }^{4}$ Although rupture may involve the intraventricular septum and the papillary muscle, the free wall of the left ventricle is by far the most common. ${ }^{5}$ About $95 \%$ of cardiac ruptures occur in the first week, with $40 \%$ of the cases within the first 24 hours post-AMI. Rupture rarely occurs after the $10^{\text {th }}$ day, when scarring has already taken place. ${ }^{5,6}$ The anatomopatho- logical findings of three cases of rupture of the myocardium, as a complication of a recent AMI, are presented.

\section{Method}

In our study, three cases of myocardial rupture post-AMI were studied in individuals autopsied at the Clinical Hospital of the Triângulo Mineiro Federal University (Uberaba - Minas Gerais - Brazil). Our investigation includes all the cases of autopsied patients in the last 30 years, during the period from 1979 to 2009, with a diagnosis of cardiac rupture as a result of a recent acute myocardial infarction. The anatomopathological findings are presented, as well as the importance of carrying out the autopsies in order to confirm the diagnosis. Our study was approved by the Research Ethics Committee of UFTM with protocol number 56433316.3.0000.5154.

\section{Results}

Autopsy findings

Case 1: Female patient, 52 years, non-white, married, housewife, born in Montes Claros (Minas Gerais), residing in Canal São Simão (Goiás). The patient was brought to the hospital in a clinical state suggestive of AMI, progressing with the appearance of a precordial systolic murmur, and died before surgery on January 19, 1979. The cause of death was 
ischemic heart disease. In the anatomopathological examination, the heart weighed $310 \mathrm{~g}$ and the heart weight to body weight ratio was $0.57 \%$. There had been a recent transmural infarction measuring about $3 \mathrm{~cm}$ in length in the lower third of the interventricular septum and anterior wall of the left ventricle, with rupture of the septum and consequent interventricular communication in the lower front portion of the septum, measuring about $1 \mathrm{~cm}$ in diameter. There was severe atherosclerosis in the left coronary artery and its branches, especially in the anterior descending and the circumflex branches, with a recent thrombus in the anterior descending artery. Passive hepatic congestion (weight $1,490 \mathrm{~g}$ ) and renal congestion (right kidney weight $140 \mathrm{~g}$; left $150 \mathrm{~g}$ ) with atherosclerosis and degenerative phenomena in the tubules were observed, as well as pulmonary (weight of the right lung $480 \mathrm{~g}$; left $400 \mathrm{~g}$ ), encephalic (weight 1,000 g) and inferior limb edema. Moderate atherosclerosis in the aorta with atheroma and fibrous plaques was also observed.

Case 2: Male patient, 67 years, white, single, born in Santa Juliana (Minas Gerais), residing in Uberaba (Minas Gerais), agricultural worker, died on August 22, 1980. He presented hypertensive and ischemic heart disease. There had been a recent infarction with intracardiac thrombosis, affecting the lower third of the interventricular septum in its right half, apex of the left ventricle and right ventricle, measuring in its largest diameters about 4.5 by 3.5 $\mathrm{cm}$. Rupture in the apex of the right ventricle with $0.4 \mathrm{~cm}$ in length and hemopericardium. Atherosclerosis was found in the left coronary, especially in the front interventricular branch, calcification and recent thrombosis. The lungs were edematous.

Case 3: Male patient, 67 years, white, married, born in Ipiau (Bahia), residing in Uberaba (Minas Gerais), retired carpenter, died on August 23, 2007. The patient had diabetes mellitus, was admitted to the emergency room in a state suggesting non-controlled asthma or chronic obstructive lung disease. He died suddenly on the $4^{\text {th }}$ day, after lung function stabilization. On autopsy, hypertensive heart disease and ischemic heart disease were verified. There was global hypertrophy of the myocardium, especially in the left ventricle, with cardiac weight of $470 \mathrm{~g}$ and the heart weight to body weight ratio was $0.71 \%$. A recent infarction was observed, in accordance with the upper-posterior region of the left ventricle, next to the coronary circumflex artery, measuring about 2.0 by $1.0 \mathrm{~cm}$, with a recent rupture of $0.5 \mathrm{~cm}$, and consecutive hemopericardium (Figure 1). There was marked atherosclerosis of the aorta, especially of the thoracic portion and its main branches. The lungs presented edema and congestion (right lung $435 \mathrm{~g}$; left $494 \mathrm{~g}$ ).

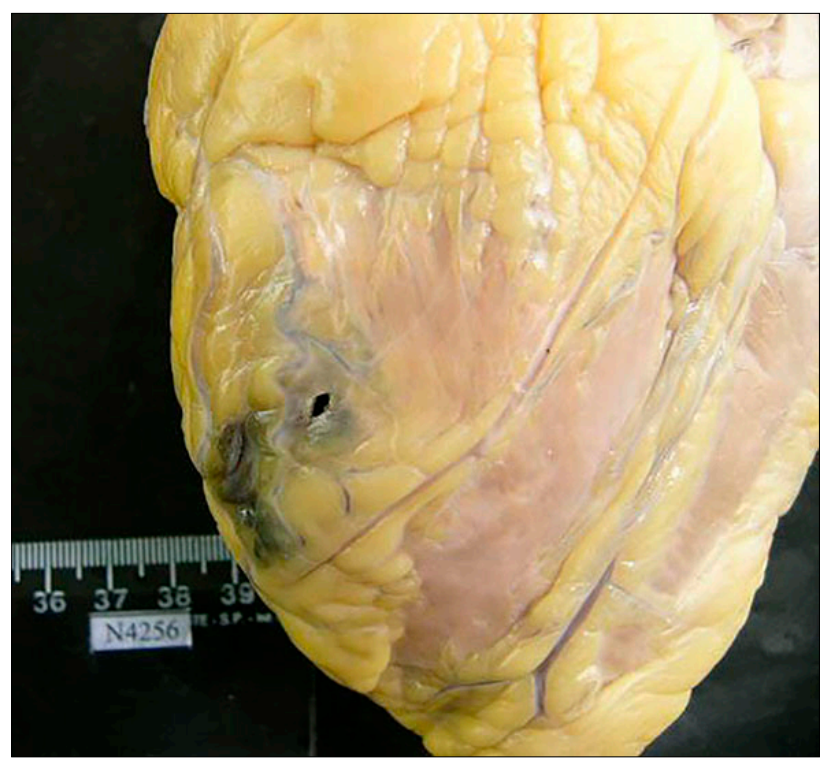

FIGURE 1 Case 3: Heart with a recent infarction corresponding to the upper-posterior area of the left ventricle and a recent rupture of $0.5 \mathrm{~cm}$.

\section{Discussion}

Our study includes all the cases of autopsied patients in the last 30 years, during the period from 1979 to 2009, with a diagnosis of cardiac rupture as a result of a recent, acute myocardial infarction. In this period, the percentage of AMI with rupture of the myocardium was $0.2 \%$.

Risk factors for rupture of the myocardium post-AMI include older age, diabetes mellitus and systemic arterial hypertension. In only one case, that of the patient who developed interventricular communication, there was doubt regarding the pre-death diagnosis. Rupture of the right ventricle with hemopericardium is also rare, and, to our knowledge, has never been reported in a series of cases. ${ }^{5,6}$

Ventricular rupture post-AMI occurs in 1 to $4 \%$ of cases, and is responsible for about $5 \%$ of premature deaths after acute myocardial infarction. ${ }^{1}$ Strong suspicion and confirmation by means of echocardiography are important for the diagnosis and eventual surgical intervention, which is currently the only way of treating this condition. ${ }^{4-6}$

Although there is a worldwide trend of a lower number of autopsies, this diagnostic method continues to be important as a form of quality control of the clinical diagnosis made while the patient is alive, and the verification of the agreement of the methods. Autopsies are not only important for medical teaching, but may also help to elucidate unexpected deaths, including those of hospitalized patients, as in the case of our series. 


\section{ACKNOWLEDGMENTS}

We would like to thank CNPq, CAPES, FAPEMIG, and FUNEPU for their financial support.

\section{Resumo}

Ruptura do miocárdio em corações com IM autopsiados

Embora a ruptura do miocárdio ocorra em apenas 2 a 4\% dos casos de infarto agudo do miocárdio (IAM), está associada a alta mortalidade, principalmente em decorrência do estado de choque cardiogênico agudo. São apresentados os achados anatomopatológicos de três casos de ruptura do miocárdio de pacientes autopsiados nos últimos 30 anos, com diagnóstico de ruptura cardíaca em decorrência de IAM. Nesse período, a porcentagem de IAM com ruptura do miocárdio foi de $0,2 \%$. Os fatores de risco para ruptura do miocárdio pós-IAM incluem idade avançada, arteriosclerose, diabetes mellitus e hipertensão arterial sistêmica.
Palavras-chave: autópsia, choque cardiogênico, infarto do miocárdio, ruptura cardíaca.

\section{References}

1. Figueras J, Cortadellas J, Soler-Soler J. Left ventricular free wall rupture: clinical presentation and management. Heart 2000; 83(5):499-504.

2. Birnbaum Y, Fishbein MC, Blanche C, Siegel RJ. Ventricular septal rupture after acute myocardial infarction. N Engl J Med. 2002; 347(18):1426-32.

3. Skehan JD, Carey C, Norrel MS, de Belder M, Balcon R, Mills PG. Patterns of coronary artery disease in post-infarction ventricular septal rupture. $\mathrm{Br}$ Heart J. 1989; 62(4):268-72.

4. Menon V, Webb JG, Hillis LD, Sleeper LA, Abboud R, Dzavik V, et al. Outcome and profile of ventricular septal rupture with cardiogenic shock after myocardial infarction: a report from the SHOCK Trial Registry. SHould we emergently revascularize Occluded Coronaries in cardiogenic shocK? J Am Coll Cardiol. 2000; 36(3 Suppl A):1110-6.

5. Shapira I, Isakov A, Burke M, Almog C. Cardiac rupture in patients with acute myocardial infarction. Chest. 1987; 92(2):219-23.

6. Wilansky S, Moreno CA, Lester SJ. Complications of myocardial infarction. Crit Care Med. 2007; 35(8 Suppl):S348-54. 